\title{
Does Weather Has Same Effect on Different Countries Stock Market Return
}

\author{
Sayed Kifayat Shah (Corresponding Author) \\ School of Management, Northwestern Polytechnical University Shaanxi \\ Xian, China \\ E-mail: skifss_20@qq.com \\ Yang Yiwen \\ School of Management, Northwestern Polytechnical University Shaanxi \\ Xian, China \\ E-mail: yangyw@nwpu.edu.cn
}

Farman Ali

School of Mathematics and Statistics, Beijing Institute of Technology China

E-mail: Fasahi192@gmail.com

Received: April 20, 2018 Accepted: June 5, 2018 Published: August 25, 2018

doi:10.5296/ijssr.v6i2.13034 URL: http://dx.doi.org/10.5296/ijssr.v6i2.13034

\begin{abstract}
In the field of behavioral finance mood, emotions and other different effecting factors have been investigated regarding stock market return. Weather is one of the most important and vital factor that has been analyzed. In this empirical study the two different stock exchanges (Eastern Asian and South Asian) are compared with respect to the weather variable temperature. The analysis and investigation has been made by utilizing the six years record of both stock exchange (China, Pakistan) indexes (SSE-180, KSE 100). The Autoregressive (AR) Conditional Heteroscedasticity $(\mathrm{GARCH})$ technique has been utilized for analysis. It has been found that temperature is the most affecting factor that has negative effect on both stock exchanges. The effect of temperature on both stock exchanges has been compared and found
\end{abstract}


that Eastern Asian Country have more effect as compared South Asian country. The results are given in detail by using Eviews Package.

Keywords: KSE-100, SSE-180, temperature, stock market return, AR-GARCH Model

\section{Introduction}

In financial system stock market provides a best platform for trading financial assets like bonds, stocks and many other products. As a secondary market it helps to increase individual wealth, country economic growth and employment opportunities and many more. Better (bad) performance of stock markets means healthy (unhealthy) economies.

Without using an option of debit when company needs to raise funds, it floats their shares in stock market through IPO (Initial public offering) for the first time. Registered companies issue it either through open market or to the existing shareholders. Usually there are two types of investors in the market, Bullish and Bearish who take advantages and profit according to their own mind set by investing in market.

A number of micro/macro variables affect the stock market return relative to their intensity. Weather is one of the most effecting factors. Psychologist argued that weather influence human behavior and mood which leads to rational/optimal decision making while investing in stock market. This idea was first discussed in (Psychology of stock market) written by Seldom in 1912. Many theoretical and numerical studies (Saunders, 1993; Cao \& Wei, 2005; Frijda, 1998; Schwartz, 1990; Loewenstein et at., 2001) in the field of psychologies suggest that weather influenced human mood and behavior which leads to influences stock market return.

As the significant correlation between weather and stock market return receives attention so many other weather factors have been examined in recent studies too. Although not all the researchers find the same results, still this topic is important that is what weather variables affect stock return and what cannot. Even though a rich literature concerning this topic is available, however no comparative research has been conducted to find out the effects of weather on stock returns in developing countries especially Pakistan and China.

China is one of the largest and quickest emerging economies in the world from last few decades and Shanghai stock market has a crucial role in it. A number of indexes used in SSE (Shanghai Stock Exchange). The SSE-180 will be investigated in this research. The second is Karachi stock market (Pakistan), the well-known and oldest market with a daily average turnover of 525.15 million shares. We will take the KSE-100 index of best 100 performing companies based on their volumes.

This study examine the impact of some important weather variable temperature in main cities Shanghai(China) and Karachi (Pakistan) in order to know whether these factors have same impact or different and people behave differently or not. On the other hand its perpose is to know whether the people of different geographical locations have the same response to the temperature or not.

Rest part of the study is organized as follows: section 2 of the study provides a literature 
review related to the issue, section 3 discussed Methodology of the research, section 4 discussed results while section 5 discussed the conclusion of the study.

\section{Literature Review}

Stock market investor is now well aware of the weather effect on mood which is a behavioral phenomenon. People behavioral feeling like mood and emotions certainly effects their decisions while investing in market (Schwartz, 1990). Many other studies also investigated the depth of weather variable on stock market return. The significant negative correlation between cloud cover and stock market return index was studied by many researchers (Saunders, 1993; Hirshleifer \& Shumway, 2003; Cheng, 2008) etc. According to Mehra, T., Sah, R (2002) the behavior of people is positive in sunny days while negative in cloudy days regarding investment decisions. Analyzing the data from 1927 to 1989 of New York stock exchange the Saunders (1993) found that the mood of investors is usually optimistic/ pessimistic in sunny/cloudy days while investing in stock market. The same result was confirmed by Hirshleifer and Shumaway (2003) by analyzing the data of twenty-six stock market. Bell (2003) found that people feel angry and impatient at a temperature greater than $84.21 \mathrm{~F}$ while others psychologist argued that nippy makes people upset and impatient but cold temperature does not have much significant effect on human behavior. Keef and Roush (2004) found that cloud cover have no influence on New Zealand Stock exchange return while have only a small influence of temperature on return. agric, T., Markovic-Hribernik, T., Strasek, S., and Jagric (2010) analyzed that making investment decision in any financial market temper is an important indicator and factor so investor must give importance to it while taking decision for future stock values. Howarth and Hoffman (1984) found the greatest influence of temper and feeling on temperature, sunshine and humidity. Particularly they found that people have aggressive feelings when the temperature is between $-8{ }^{\circ} \mathrm{C}$ and $-28{ }^{\circ} \mathrm{C}$. According to Clore and Schwartz (1983), in sunny days people rate their life satisfaction higher while less in cloudy and rainy days. Sriboonchitta et al. (2011) analyzed the data of Thailand stock market by using (AR-GARCH) model and analyzed the relationship between stock market return and temperature. Shortly there is an enough literature on the relationship of weather variables, behavior and stock market return, (e.g., Allen and Fisher (1978) Wyndham (1969) Moos (1976). Kaustia and Rantapuska (2011) examine the influence of lunar phases, daylight, precipitation and sunlight on the return and volume of the Finnish stock market and found positive relationship for lunar phases and sun light while negative for daylight and precipitation while no support temperature and seasonal affective disorder (SAD). Bassi et al. (2013) also entail that good weather improves the mood which leads to reduce the risk aversion. (Apergis et al., 2017) analyzed the impact of unusual weather condition in New York and London and confirm that unusual weather can affect global stock market. Jae H. kim (2017) evaluate the significant weather impact on stock return and found that the number of sunspots are highly significant although it have negligible impact on stock return. Muhammad fayaz sheikh at el. (2017) analyzed six south Asian countries by studying the effect of mood proxy variables on stock return and found that these variables have considerable effect on south Asian market.

Based on accessible literature, the current research is trying to find out positive/negative 
relationship of temperature and stock market return of two different countries (China and Pakistan ) having different weather condition in a year and compare it whether it has the same effect or not by using the model AR- GARCH.

\section{Methodology}

In this research, the secondary type daily data is obtained from the official website of Shanghai stock exchange and Karachi stock exchange during last 5 years starting from January 2011 till May 2016 while the daily weather (average temperature) data is obtained from wunderground metrological data providing website. The SSE-180 index is utilized for Shanghai stock return while KSE-100 for Karachi stock Return. The daily index return is calculated by using the following equation:

$\left(R T N_{t}\right)=\ln \left(P_{t} / P_{t-1}\right)$

Where $R T N_{t}$ is the Daily return index at time $\mathrm{t}$ while $P_{t}$ and $P_{t-1}$ represents the prices at time $\mathrm{t}$ and $t-1$.

Equation for Daily Average Temperature calculation is given as:

$$
T M_{\text {Avg }}=\frac{T M_{\text {High }}+T M_{\text {Low }}}{2}
$$

The model used for calculation is AR-GARCH ( $p$ q) which is defined in the equation given below:

$$
X_{t}=c+\sum_{i=1}^{p} \varphi X_{t-1}+\varepsilon
$$

Where $(\mathrm{p}, \mathrm{q})$ represents the order of equation and $\varphi \mathrm{i}$ are the parameters, c represents the constant while $\varepsilon$ represents the white noise.

For simple GARCH (1 1), Conditional mean and variance equations are given as:

$$
\begin{aligned}
& Y_{t}=X_{t} \theta^{\prime}+\epsilon_{t} \\
& \sigma_{t}^{2}=\omega+\alpha \epsilon_{t-1}^{2}+\beta \sigma_{t-1}^{2}
\end{aligned}
$$

The mean equation (4) is a function of exogenous variable with an error term while conditional variance equation (5) has first order lag information and forecast one period ahead. The term $a$ is constant, $\boldsymbol{\epsilon}_{i-1}^{2}$ represents the ARCH term means previous period volatility, $\sigma_{t-1}^{2}$ GARCH term represents the last period forecast variance. As AR-GARCH (1 1) model is used in this research so the conditional mean and variance equations are given below:

$$
R_{t}=C_{0}+C_{1} R_{t-1}+C_{2} T M_{t}+\varepsilon_{t}
$$


$\omega_{t}^{2}=\omega+\alpha \epsilon_{t-1}^{2}+\beta o_{t-1}^{2}+e$

Where $\mathrm{R}$ is the return at time $\mathrm{t}$ and $\mathrm{t}-1, \mathrm{TM}$ is the temperature at time $\mathrm{t}$ and $\varepsilon$ is an error term while the 7 and 5 equations are same.

In order to analyze the effect, the daily stock market return data with daily average temperature has been analyzed of both stack exchanges Shanghai and Karachi. To make the data Stationary the unit root test is used and makes it stationary with first difference. For ARCH model usually normal distribution, student $t$, distribution and GED distribution are used in EVIEWS package. The Normal (Gaussian) is used for Shanghai and Student $t$ is used for Karachi separately.

Table 1. AR-GARCH result under Normal (Gaussian) for Shanghai Stock Market

\begin{tabular}{|c|c|c|c|c|}
\hline \multicolumn{3}{|c|}{ ADF-Test Statistic } & T-Statistic & Probability* \\
\hline \multicolumn{3}{|c|}{ Return(RTN) } & -37.71218 & $<0.01$ \\
\hline \multicolumn{3}{|c|}{ Temperature(TM) } & -19.56921 & $<0.01$ \\
\hline \multirow[t]{3}{*}{ Critical Value Test } & 1 Percent Level & -4.94 & & \\
\hline & 5 Percent Level & -4.44 & & \\
\hline & 10 Percent Level & -4.19 & & \\
\hline Variance & Coefficient & S.E & Z-Statistic & Probability \\
\hline \multirow[t]{2}{*}{$C_{0}$} & -0.000206 & 0.000336 & -0.612722 & 0.5405 \\
\hline & $-7.40 \mathrm{E}-06$ & $3.72-06$ & -1.987406 & 0.0469 \\
\hline$R_{t-1}$ & 0.009873 & 0.028695 & 0.344048 & 0.0005 \\
\hline \multicolumn{5}{|c|}{ Variance Equation } \\
\hline$\omega$ & $1.36 \mathrm{E}-06$ & $4.95 \mathrm{E}-07$ & 2.749729 & 0.0060 \\
\hline$\alpha$ & 0.053289 & 0.005654 & 9.424256 & 0.0000 \\
\hline$\beta$ & 0.941920 & 0.005524 & 170.5189 & 0.0000 \\
\hline$\alpha+\beta$ & 0.995209 & & & \\
\hline R-Squared & 0.001432 & & & \\
\hline ADJ-R & 0.000049 & & & \\
\hline AKA-Criteria & -5.699400 & & & \\
\hline SKH-Criteria & -5.677518 & & & \\
\hline L-Likli-Hood & 4129.516 & & & \\
\hline DW-Statistic & \multicolumn{2}{|l|}{1.964640} & & \\
\hline \multicolumn{5}{|c|}{ ARCH-LM Test: ARCH } \\
\hline F-Stat & 1.812635 & & Pro.F(1,1444) & 0.1784 \\
\hline OB-R-squared & 1.812870 & & Pro. Chi-sq(1) & 0.1782 \\
\hline \multicolumn{3}{|c|}{ Correlogram of Standardized Residuals Squared Test } & \multicolumn{2}{|c|}{ Histogram Normality Test } \\
\hline Q-Stat & Minimum1.8175 & Maximum38.670 & Jarque-Bera & 229.3616 \\
\hline Prob* & Minimum 0.178 & Maximum 0.350 & Probability* & 0.0000 \\
\hline
\end{tabular}


Table 2. AR-GARCH results under Normal (Gaussian) for Karachi Stock Market

\begin{tabular}{|c|c|c|c|c|c|c|}
\hline \multicolumn{5}{|c|}{ ADF-Test Statistic } & T-Statistic & Probability* \\
\hline \multicolumn{5}{|c|}{ Return(RTN) } & -34.06565 & $<0.01$ \\
\hline \multicolumn{5}{|c|}{ Temperature(TM) } & -25.87016 & $<0.01$ \\
\hline \multirow{3}{*}{\multicolumn{2}{|c|}{ Critical Value Test }} & \multicolumn{2}{|c|}{1 Percent Level } & -4.94 & & \\
\hline & & \multicolumn{2}{|c|}{5 Percent Level } & -4.44 & & \\
\hline & & \multicolumn{2}{|c|}{10 Percent Level } & -4.19 & & \\
\hline \multicolumn{2}{|l|}{ Variance } & \multicolumn{2}{|c|}{ Coefficient } & S.E & Z-Statistic & Probability \\
\hline \multicolumn{2}{|l|}{$C_{0}$} & \multicolumn{2}{|c|}{-0.000858} & 0.000200 & -4.280591 & 0.0000 \\
\hline & & \multicolumn{2}{|c|}{0.000131} & $6.64 \mathrm{E}-05$ & 1.966662 & 0.0492 \\
\hline \multicolumn{2}{|l|}{$R_{t-1}$} & \multicolumn{2}{|c|}{0.094870} & 0.026809 & 3.538718 & 0.0004 \\
\hline \multicolumn{7}{|c|}{ Variance Equation } \\
\hline \multicolumn{2}{|l|}{$\omega$} & \multicolumn{2}{|c|}{$4.32 \mathrm{E}-06$} & $1.50 \mathrm{E}-06$ & 2.878924 & 0.0040 \\
\hline \multicolumn{2}{|l|}{$\alpha$} & \multicolumn{2}{|c|}{0.130163} & 0.030061 & 4.330014 & 0.0000 \\
\hline \multicolumn{2}{|l|}{$\beta$} & \multicolumn{2}{|c|}{0.833206} & 0.034346 & 24.25937 & 0.0000 \\
\hline \multicolumn{2}{|l|}{$\alpha+\beta$} & \multicolumn{2}{|c|}{0.96336} & & & \\
\hline \multicolumn{2}{|c|}{ R-Squared } & \multicolumn{2}{|c|}{0.011138} & & & \\
\hline \multicolumn{2}{|l|}{ ADJ-R } & \multicolumn{2}{|c|}{0.009691} & & & \\
\hline \multicolumn{2}{|c|}{ AKA Criteria } & \multicolumn{2}{|c|}{-6.884403} & & & \\
\hline \multicolumn{2}{|c|}{ SKH-Criteria } & \multicolumn{2}{|c|}{-6.857718} & & & \\
\hline \multicolumn{2}{|c|}{ L-Likli-Hood } & 4722 & & & & \\
\hline DW-Statis & & 1.99 & & & & \\
\hline & & & & CH-LM Test: & $\mathrm{ARCH}$ & \\
\hline F-Stat & & 999 & & & Pro.F(1,1 & 0.6453 \\
\hline OB-Rsquared & & 2276 & & & Pro.Chis & 0.6450 \\
\hline Correlogra & of $s$ & dardized & & uared Test & & Normality Test \\
\hline Q-Stat & & um0.212 & & mum 37.183 & Jarque-E & 333.1990 \\
\hline Prob* & & num0.645 & & Imum 0.414 & Probabil & 0.0000 \\
\hline
\end{tabular}

Table 1 and 2 represent the results of AR (1)-GARCH (1 1 ) model with normal (Gaussian) for Shanghai stock exchange and Karachi stock exchange respectively. These two tests are performed separately in order to analyze the effect. At level 5\% and 10\% the coefficients of return and temperature have negative affect that are -37.71218 and -19.56921 for Shanghai and-34.06565,-25.87016 for Karachi which shows that both data series are stationary. The reason to use the Unit root test is that it is more durable and affective. The conditional variance will reveal long term perseverance of volatility because the GARCH is perseverance and are greater than ARCH term also the volatility shocks are quite persistent as sum of $\mathrm{ARCH}$ and GARCH are $(0.995209,0.96336)$ respectively which are nearly equal to one. Both the temperature coefficients $(-7.40 \mathrm{E}-06,0.000131)$ are low and significant (Probability value $0.0469,0.0492)$ respectively. It also shows that Shanghai Stock Market have more negative 
relationship as compared to Karachi Stock Market which have positive relationship. The reason is that the average temperature of Karachi is much more as compared to Shanghai. Also the people of Karachi face almost warm weather during a year as compared to Shanghai. The ARCH-LM Heteroskedasticity test shows that probability value 0.1782, 0.6450are greater than $5 \%$ showing that there is no ARCH effect, shows that residuals have no Heteroskedasticity. The correlogram squared residuals test also shows that there is no serial correlation as the probability values(Minimum 0.178, Maximum 0.350, Minimum 0.645, Maximum 0.414) respectively are greater than 5\%. Although the Histogram Normality Test shows that residuals in data are not normal as probability value is $(0.00,0.00)$ and jarquae-Bera value $(229.3616,333.1990)$ is much high yet still we can apply the model.

\section{Conclusions}

A number of Empirical evidence shows that human behavior is effected by a number of environmental factors like Temperature clouds, rain humidity wind speed etc that's why the traditional approach of investors rationality is now meaningless. Psychological literature shows that temperature is one of the most significant metrological variables which effect human mood and behavior. Evidence suggest that high temperature causes apathy, hysteria and aggression while low temperature leads to aggression and it's a natural to imagine that temperature will affect the behavior of investor.

In this research, a relationship between temperature and stock market return has been conducted by using the well-known indexes of (SSE, KSE) and compared with each other. The analysis revel a positive relationship for Karachi while negative for Shanghai stock market return. It also shows that area where the weather has less variation in the form of temperature will be less affected or can say positively affected as compared to more variation areas in the form of weather. The reason is that the people of Karachi usually face a hot temperature as compared Shanghai so that's why temperature of Karachi has positive impact on behavior of people there. Although effect of weather on stock market return is an unobservable phenomena yet the time series analysis propose that weather does have an impact.

For long run investments in China or in Pakistan, investors should judge climate change independently and especially in Pakistan. Limitation of this research is that China is a vast country and one part of temperature is completely different from other part. One the other hand the Geographical area of Pakistan is much smaller than China. So for research in future many other weather variables including temperature from all parts (North, West, South, and East) of China should examine jointly. The extreme cold and hot weather should also be compare of these two countries, as both countries will be very close in coming future because of Chinese firm's huge investment in Pakistan.

\section{References}

Allen, A. M., \& Fisher, G. J. (1978). Ambient temperature effects on paired associate learning. Ergonomics, 21(2), 95-101. 
Apergis \& Rangan. (2017). Can (unusual) weather conditions in New York predict South African stock returns? Research in International Business and Finance, 41, 377-386.

Anna Bassi. (2013). Weather, mood, and voting: An experimental analysis of the effect of weather beyond turnout. The 6th Annual NYU-CESS Experimental Political Science Conference.

Cao, M., \& Wei, J. (2005). Stock market returns: a note on temperature anomaly. J Banking Finance, 29, 1559-73.

Chang, S. C., Chen, S. S., Chou, R. K., \& Lin, Y. H. (2008).Weather and intraday patterns in stock returns and trading activity. Journal of Banking \& Finance, 32, 1754-1766.

Cunningham, M. R. (1979). Weather, mood, and helping behavior: Quasi experiments with the sunshine Samaritan. Journal of Personality and Social Psychology, 37(11), 1947.

Frijda, N. (1988). The laws of emotion. Cognition and Emotion, 1, 235-258,

Hirshleifer, D., \& Shumway, T. (2003). Good day sunshine: stock returns and the weather. Journal of Finance, 58, 1009-1032.

Jagric, T., Markovic-Hribernik, T., Strasek, S., \&Jagric, V. (2010). The power of market mood - Evidence from an emerging market. Economic Modelling, 27(5), 959-967.

Jae, H. K. (2017). Stock returns and investors' mood: Good day sunshine or spurious correlation?. International Review of Financial Analysis, 52, 94-103.

Kaustia, \& Rantapuska. (2011). Does mood affect trading behavior?. The 5th Nordic Conference on Behavioral and Experimental Economics for comments.

Mehra, R., \& Sah, R. (2002). Mood fluctuations, projection bias and volatility of equity prices. Journal of Economic Dynamics and Control, 26, 869-887.

Moos, R. H. (1976). The Human Context: Environmental Determinants of Behaviors. Wiley, New York.

P.A. Bell, T.C. Greene, J.D. Fisher, A. Baum, Environmental Psychology, Publisher Belmont, Wadsworth, 2003.

Pilcher, J.J., Eric, N., Busch, C., 2002. Effects of hot and cold temperature exposure on performance: Ameta-analytic review. Ergonomics 45 (10), 682-698.

Rind, B. (1996). Effects of beliefs about weather conditions on tipping. Journal of Applied Social Psychology 26, 137-147.

Sheikh, M. F. (2017). Weather effects on stock returns and volatility in South Asian markets. Asia-Pacific Financial Markets.

S.P. Keef, M.L. Roush, The weather and stock returns in New Zealand, Q. J. Bus. Econ. 41 (2004) 61-79.

Sanders, J. L., \& Brizzolara, M. S. (1982). Relationship between mood and weather. Journal 


\section{Macrothink}

of General Psychology, 107, 157-158.

Saunders, E. M. (1993). Stock prices and Wall Street weather. American Economic Review, $83,1337-1345$.

Schwartz, N. (1990). Feelings as information: informational and motivational functions of affective states. In Higgins and Sorrentino, Handbook of Motivation and Cognition NewYork, Guildford Press. 2, 527-561.

Schwarz, N., \& Clore, G. L. (1983). Mood, misattribution and judgments of well-being: indirect functions of affective states. Journal of Personality and Social Psychology, 45, 513-523.

Sriboonchitta, S., Chitip, P., Sriwichailamphan, T., \& Chaiboonsri, C. (2011). Stock market returns and the temperature effect. Thailand International Research Journal of Management and Business Studies, 1(1), 012-016.

Watson, D. (2000). Situational and environmental influence on mood. In: Mood and Temperament. Guilford Press, New York. (Chapter 3).

Wyndham, H. C. (1969). Adaptation to heat and cold. Environmental Research, 2, 442-469.

\section{Copyright Disclaimer}

Copyright for this article is retained by the author(s), with first publication rights granted to the journal.

This is an open-access article distributed under the terms and conditions of the Creative Commons Attribution license (http://creativecommons.org/licenses/by/3.0/). 